\title{
Neurologic complications in adult living donor liver transplant patients: an underestimated factor?
}

\author{
Fuat Hakan Saner · Julia Gensicke - Steven W. M. Olde Damink - Goran Pavlaković • \\ Juergen Treckmann · Marc Dammann · Gernot M. Kaiser · Georgios C. Sotiropoulos • \\ Arnold Radtke · Susanne Koeppen · Susanne Beckebaum • Vito Cicinnati · Silvio Nadalin • \\ Massimo Malagó · Andreas Paul · Christoph E. Broelsch
}

Received: 20 January 2009/Revised: 8 August 2009/Accepted: 18 August 2009/Published online: 1 September 2009

(c) Springer-Verlag 2009

\begin{abstract}
Liver transplantation is the only curative treatment in patients with end-stage liver disease. Neurological complications (NC) are increasingly reported to occur in patients after cadaveric liver transplantation. This retrospective cohort study aims to evaluate the incidence and causes of NC in living donor liver transplant (LDLT) patients in our transplant center. Between August 1998 and December 2005, 121 adult LDLT patients were recruited into our study. $17 \%$ of patients experienced $\mathrm{NC}$, and it occurred significantly more frequently in patients with alcoholic cirrhosis (42\%) and autoimmune hepatitis (43\%) as compared with patients with hepatitis B or C $(9 / 10 \%$,
\end{abstract}

F. H. Saner ( $₫)$ · J. Gensicke · J. Treckmann · M. Dammann .

G. M. Kaiser - G. C. Sotiropoulos - A. Radtke - S. Beckebaum ·

S. Nadalin · M. Malagó - A. Paul · C. E. Broelsch

Department of General-, Visceral- and Transplant Surgery,

University Hospital Essen, Hufelandstr. 55, 45122 Essen,

Germany

e-mail: fuat.saner@uni-due.de

S. W. M. O. Damink

Department of Surgery, Maastricht University, Maastricht,

The Netherlands

S. W. M. O. Damink · M. Malagó

Department of Surgery, University College London Hospital,

UCL, London, UK

G. Pavlaković

Center for Anesthesiology,

Emergency and Intensive Care Medicine,

University Clinic Goettingen, Goettingen, Germany

S. Koeppen

Department of Neurology, University Essen, Essen, Germany

V. Cicinnati

Department of Gastroenterology and Hepatology,

Essen, Germany
$P=0.013)$. The most common NC was encephalopathy $(47.6 \%)$ followed by seizures $(9.5 \%)$. The choice of immunosuppression by calcineurin inhibitor (Tacrolimus or Cyclosporin A) showed no significant difference in the incidence of NC (19 vs. 17\%). The occurrence of NC did not influence the clinical outcome, since mortality rate, median ICU stay and length of hospital stay were similar between the two groups. Most patients who survived showed a nearly complete recovery of their NC. NCs occur in approximately 1 in 6 patients after LDLT and seem to be predominantly transient in nature, without major impact on clinical outcome.

Keywords Encephalopathy - Liver transplantation . Neurological complication - Immunosuppression · Living donor
Abbreviations
NC Neurologic complication
TAC Tacrolimuns
CSA Cyclosporine A
AST Aspartate transaminase
ALT Alanine transaminase
ESLD End-stage liver disease
LDLT Living donor liver transplantation

\section{Introduction}

Liver transplantation (LT) has been performed since 1963 [29]. At that time all patients died from uncontrolled bleeding or acute rejection. The first successful liver transplantation was performed in 1967 [28]. Since that time 
survival rates of patients undergoing LT have improved markedly, mostly due to improved peri-operative care, operative techniques and improved immune suppressive therapy [7, 23]. Improved long-term survival after LT has led to increasing awareness of the occurrence of neurological complications (NC) in recent years [15, 24, 27]. NCs in patients following LT are reported to occur in up to $75 \%$ of cases $[1,8,9,13,21,22]$. The main diagnoses of $\mathrm{NC}$ are encephalopathy, seizure, immunosuppressant related neurotoxicity, and peripheral nerve damage [1, 31, 32]. Due to organ shortage, the first clinical LDLT program was started by Broelsch [4, 5] at the University of Chicago in 1989 and has become an alternative approach for adult and pediatric liver transplantation in many centers throughout the world [17]. We conducted this retrospective cohort study to evaluate the incidence of NCs in LDLT patients in our center.

\section{Patients and methods}

The study was conducted in accordance with the Declaration of Helsinki. Adult living donor liver transplant recipients transplanted at the Department of General-, Visceral- and Transplant Surgery, University DuisburgEssen, Germany between October 1998 and December 2005 were included in the analysis. Exclusion criteria were pediatric patients (age $<18$ years) and incomplete patient records. Our policy towards the selection of patients appropriate for LDLT has been described elsewhere [17, 33].

All operations were performed using standard surgical techniques and a standardized anesthesia protocol was applied to all patients. Patients were treated postoperatively in a single intensive care unit applying standardized care consisting of triple immune suppression [corticosteroids, mycophenolatmofetile (MMF) and tacrolimus (TAC) or cyclosporine A (CSA)], antimicrobial prophylaxis and selective digestive decontamination [26]. Daily trough levels of the calcineurin inhibitors (CNIs) (TAC or CSA) were measured for adjusting the daily dose. Rejection episodes of the graft were treated with $500 \mathrm{mg}$ prednisolone three times daily intravenously. Renal replacement therapy (CVVHD) was initiated if creatinine exceeded $2.5 \mathrm{mg} / \mathrm{dL}$, if blood urea nitrogen exceeded $100 \mathrm{mg} / \mathrm{dL}$ or if patients had impaired oxygenation due to volume overload. Blood samples were collected 1 day before liver transplantation and then every morning after liver transplantation until the patient was discharged from the ICU. Laboratory routine work-up was performed daily and included at least total bilirubin, aspartate transaminase (AST), alanine transaminase (ALT), creatinine, c-reactive protein (CRP), hemoglobin, leukocytes, platelets and international normalized ratio (INR). The follow-up was 1 year for all patients.

\section{Definition}

Diagnoses of NCs were assessed by neurologic examination, cerebral computed tomography (cCT) or cerebral magnetic resonance tomography (cMRT). A central nervous system complication was considered to occur when there was clinical and/or radiologic evidence of central nervous system damage which was not associated with a poor graft function, sepsis or other diseases that could be associated with central nervous system signs. Delirium, stupor and coma with regular cCT or cMRT images were grouped under the term encephalopathy.

Clinical examinations were performed by the ICU and transplantation staff. The clinical diagnoses were confirmed by neurologists.

\section{Statistical analyses}

Categorical variables were analyzed by the Chi-squared test with Yates correction. Continuous variables were analyzed by the one-way analysis of variance and $t$ test, when normal distribution was given. Non-normally distributed continuous variables were analyzed by the Kruskal-Wallis one-way analysis of variance on ranks.

The Mann-Whitney Rank Sum test was performed when the equal variance test failed; $P<0.05$ was considered significant. Data are presented as mean \pm SD.

\section{Results}

Patients

From October 1998 to December 2005, 167 living donor transplantations were performed at the surgical department of the University of Essen; of these 34 were transplantations in pediatric patients that were not enrolled into the study. Twelve of the 133 adult LDLT patients had incomplete records, so were also excluded from the study. Complete medical records of the remaining 121 adult patients were retrospectively reviewed. The primary liver diagnoses are listed in Table 1.

Incidence of neurological complications

After LDLT, $17 \%$ of patients (10 men, 11 women, age $48 \pm 14$ ) experienced NCs. The most common complication was encephalopathy, including somnolence, mental alteration and confabulation, which occurred in ten 
Table 1 Primary diagnoses

\begin{tabular}{lc}
\hline Underlying disease & Number of patients $(\%)$ \\
\hline Hepatitis C & $43(36)$ \\
Hepatitis B & $21(17)$ \\
Alcoholic cirrhosis & $14(12)$ \\
PBC/PSC & $17(14)$ \\
Autoimmune hepatitis & $7(6)$ \\
Cryptogenic & $9(7)$ \\
Miscellaneous & $10(8)$ \\
Total & $121(100)$ \\
\hline
\end{tabular}

Miscellanous: Cholangiocellular carcinoma (2), Klatskin tumor (1), M. Wilson (1), Neuroendocrine tumor (2), acute intermittent porphyria (1), sarcoma of the liver (1), hemangiosarcoma of the liver (1), $\alpha_{1}$ antitrypsine deficiency (1)

$P B C$ primary biliary cirrhosis, $P S C$ primary sclerosing cirrhosis

patients. Two patients experienced seizures, another two developed peripheral polyneuropathy. The trough levels of CSA or TAC at the time of NC onset were in the therapeutic range (for TAC $8-15 \mathrm{ng} / \mathrm{ml}$, for CSA $200-250 \mathrm{ng}$ / $\mathrm{ml})$. Miscellaneous complications occurred in seven patients [posterior leucencephalopthy (1), ischemic stroke (1), intracerebral bleeding (1), heparin-induced thrombocytopenia related ischemia (2), subarachnoidal hemorrhage (1), and pontine myelinolysis (1), see Table 2]. The patient with the ischemic stroke suffered from post transplant diabetes, whereas the patient with the intracerebral hemorrhage suffered from hypertension.

The occurrence of NC could not be explained by differences in MELD score, ICU- hospital stay or cold- and warm ischemia time between the groups (see Table 3). $52 \%$ of patients that experienced NC (11/21 patients) already showed pretransplant signs of advanced encephalopathy, as opposed to $15 \%$ (15/100 patients) in the group without NC $(P<0.001)$.

In both patient groups the clinical course of the transplanted liver graft was normal and did not differ significantly (see Table 4). We recorded a significant decline of AST on admission compared with 1 week following transplantation within each group. Bilirubin remained nearly the same 1 week after transplantation as compared

Table 2 Type of neurological complication

\begin{tabular}{lcl}
\hline Complication & Number & Incidence $(\%)$ \\
\hline Encephalopathy & 10 & 48 \\
Seizure & 2 & 10 \\
Peripheral polyneuropathy & 2 & 10 \\
Miscellaneous $^{\mathrm{a}}$ & 7 & 33 \\
Total & 21 & \\
\hline
\end{tabular}

${ }^{a}$ Miscellaneous diagnoses see text
Table 3 Perioperative patients' data

\begin{tabular}{lcc}
\hline & Patients with NC & Patients without NC \\
\hline MELD score & $18 \pm 2$ & $16 \pm 1$ \\
Ventilation time in h & $106 \pm 34$ & $99 \pm 25$ \\
ICU stay in days & $12 \pm 4$ & $11 \pm 2$ \\
Hospital stay in days & $37 \pm 6$ & $58 \pm 27$ \\
WIT (min) & $43 \pm 9$ & $42 \pm 4$ \\
CIT (min) & $224 \pm 28$ & $225 \pm 13$ \\
GBWR & $1.05 \pm 0.2$ & $1.1 \pm 0.25$ \\
1 Year survival (\%) & 74 & 70 \\
\hline
\end{tabular}

All data are given as mean $\pm \mathrm{SD}$

WIT warm ischemia time, $C I T$ cold ischemia time, GBWR graft body weight ratio

with the value on admission to the ICU. Renal function, expressed as serum creatinine concentrations, did not alter during the first week following transplantation in either group (see Tables 4, 5).

Most NCs (90\%) were encountered in the first month after LT. In the majority of cases, encephalopathy (80\%) and seizure $(60 \%)$ presented in the first 2 weeks. Only one patient experienced $\mathrm{NC}$ after hospital discharge.

Effect of the primary diagnosis on $\mathrm{NC}$

Viral hepatitis and alcoholic cirrhosis were the main causes of pre-operative liver decompensation (see Table 1). $42 \%$ of the alcoholic group and $43 \%$ of the autoimmune group showed the highest rate of NCs. The incidence of NC in these groups was significantly higher as compared to patients with hepatitis B or hepatitis C $(9.4 \%, P=0.006$ and $P=0.04$, respectively).

Patients with autoimmune hepatitis received significantly more immunosuppressive drugs preoperatively, such as prednisone or azathioprine, as compared with patients suffering from PBC or PSB [4/7 (57\%) vs. 2/17 (12\%), $P=0.02]$.

Table 4 Course of AST, bilirubin and creatinine

\begin{tabular}{llllll}
\hline & \multicolumn{2}{l}{ Patients with NC } & & \multicolumn{2}{l}{ Patients without NC } \\
\cline { 2 - 3 } \cline { 5 - 6 } \cline { 5 - 6 } & Day 0 & Day 7 & & Day 0 & Day 7 \\
\hline $\begin{array}{l}\text { AST (U/L) } \\
\begin{array}{l}\text { Bilirubin (mg/ } \\
\text { dL) }\end{array}\end{array}$ & $340 \pm 58$ & $43 \pm 12^{*}$ & & $295 \pm 49$ & $69 \pm 15^{*}$ \\
$\begin{array}{l}\text { Creatinine (mg/ } \\
\text { dL) }\end{array}$ & $1.2 \pm 0.13$ & $1.2 \pm 0.14$ & & $1.3 \pm 0.07$ & $1.5 \pm 0.14$ \\
\hline
\end{tabular}

Day 0: day of admission, Day 7: 1 week following transplantation $N C$ neurological complication

Values are given as mean $\pm \mathrm{SD}$

$* P<0.05$ 
Table 5 Effect of primary diagnosis on neurologic complication

\begin{tabular}{lcc}
\hline Underlying disease & All patients & $\begin{array}{l}\text { Patients with NC } \\
\text { post-LT (incidence of NC) }\end{array}$ \\
\hline Hepatitis C & 43 & $4(9 \%)$ \\
Hepatitis B & 21 & $2(10 \%)$ \\
Alcoholic cirrhosis & 14 & $6(42 \%)$ \\
PBC/PSC & 17 & $2(12 \%)$ \\
Autoimmune hepatitis & 7 & $3(43 \%)$ \\
Cryptogenic & 9 & $3(33 \%)$ \\
Miscellaneous & 10 & $3(30 \%)$ \\
Total & 121 &
\end{tabular}

$P B C$ primary biliary cirrhosis, $P S C$ primary sclerosing cirrhosis, $N C$ neurologic complication, $L T$ liver transplantation

Miscellanous: Cholangiocellular carcinoma (2), Klatskin tumor (1), M. Wilson (1), Neuroendocrine tumor (2), acute intermittent porphyria (1), sarcoma of the liver (1), hemangiosarcoma of the liver (1), $\alpha_{1}$ antitrypsine deficiency (1)

Influence of neurologic complications on outcome after LDLT

The occurrence of NC in patients after LDLT did not influence the main clinical outcome parameters median ICU stay, length of hospital stay or one year survival (see Table 3). The long term neurological function did not differ between the groups.

Effect of the calcineurin inhibitor on neurological complications

CSA was the predominantly used immunosuppressant in our cohort (78 of all patients), whereas 43 patients were treated with TAC. NCs occurred in $19 \%$ of TAC treated patients, and in $17 \%$ of the CSA-group $(P=0.9)$.

\section{Discussion}

The present study shows that NCs occur frequently after LDLT. The reported incidence of NC after cadaveric liver transplantation ranges from 10 to $75 \%[8,9,13,21,22]$. In the present study the rate of NCs was $17 \%$. The main clinical outcome parameters median ICU stay, hospital stay and one year survival rate did not differ between patients with and without NC. The MELD score and graft function were comparable in patients with and without NCs. Patients with alcoholic and autoimmune related cirrhosis showed a significant higher rate of NCs as compared with other diagnoses. Development of NC after LDLT was related to pre-transplant deterioration in neurological function, but was not influenced by type of immunosuppressant used.

The incidence of $\mathrm{NC}$ in $17 \%$ of patients observed in our study is comparable with other reports. Kim et al. [15] reported an incidence of $15.4 \%$ of $\mathrm{NC}$ in their LDLT patients. The incidence of NC in LT patients with a deceased donor was recorded to be $25 \%$ in the group of Mueller [20]. The highest incidence of NCs in LT patients with a deceased donor was mentioned by Ghaus et al. [13] with an incidence of $75 \%$. The reason for the higher incidence of NC in the Ghaus study [13] may be the smaller number of evaluated patients ( 21 vs. 45 patients), whereas the Mueller study [20] recruited 130 patients. Moreover, Ghaus [13] et al. also included peripheral neurologic disorderssuch as tremor, which may be responsible for this high incidence of $75 \%$ in their study.

Diffuse encephalopathy is considered to be the main NC in patients after liver transplantation [19]. Encephalopathy was also the main $\mathrm{NC}$ in the present study, with an incidence rate of $48 \%$. The cause of post-transplant encephalopathy in patients with a primary functioning graft remains unclear. Post mortem results of an anecdotal study indicate anoxic-ischemic changes as the main neuropathological findings, which could be the cause of encephalopathy [10].

The second most common cause of NC in LT patients is seizures. The reported incidence is up to $20 \%$ [16, 22]. In our study the incidence of seizures was $10 \%$ and confirmed previous data from our group, which indicates an incidence of $11.6 \%$ [22]. In the recent 10 years the rates of seizures seems to have declined. One center reported a reduction in the incidence of seizures in patients following LT from $42 \%$ [34] to $0 \%$ [31] at two different time periods. The reasons for this reduction could be improved postoperative intensive care, improvement in accurate diagnosis and treatment of metabolic disorders, and improved immunosuppressive drugs with fewer side effects.

In the present study, one patient developed central pontine myelinolysis (CPM). CPM was first described in 1959 [2] and first reported after a liver transplantation in 1978 [30]. CPM presents symmetrical demyelinating lesions at the center of the pons. Despite being first described in alcoholics and malnourished patients, several reports describe its occurrence in patients after liver transplantation, with incidence rates ranging between 1.2 and $10 \%[3,6]$. Due to study design, the incidence of CPM in autopsy studies is significantly higher as compared with clinical studies.

The etiology and pathogenesis of CPM remains unclear, though rapid correction of hyponatremia seems to be a main factor which triggers this syndrome with signs of dysarthria, paraperesis or quadriparesis [36]. The patient in our report died due to lack of causative treatment. However, in some selected cases a combination of plasmapheresis and immunoglobulins could be considered as a rescue treatment [25]. 
Furthermore, one patient developed posterior leukoencephalopathy (PLE), which was first described in 1996 [14]. This illness was recognized as a reversible syndrome of headache, visual abnormalities and hemipareses induced by severe hypertension. After successful treatment of hypertension all patients recovered. However, our group published a case of a LDLT patient, who developed a TAC related PLE 3 months after transplantation. On admission she was comatose and remained unconscious until she died [12].

It has been documented that the incidence of $\mathrm{NC}$ is higher in patients receiving liver grafts from deceased donors for alcoholic and primary biliary cirrhosis [16]. In contrast to our data, Kim et al. [15] did not find a relationship between NCs and primary liver diagnosis in LDLT patients. Our data indicate a significant higher rate of NC in patients who received a transplant for alcoholic liver disease and autoimmune hepatitis.

In our study the survival rate of patients with or without NC did not differ significantly. In a prospective clinical trial, Pujol et al. [21] showed a significant higher mortality rate for liver transplant patients with $\mathrm{NC}$ as compared to those without (55 vs. 17\%), whereas Wijdecks et al. [35] indicate no impact of NC on mortality.

The relationship between immunosuppressive therapy and the development of $\mathrm{NC}$ has been well established for calcineurin inhibitors [20]. McDiarmid [18] reported a higher incidence of NC in TAC based immunosuppression regime as compared with CSA. The incidence of major NCs such as coma, seizures, and encephalopathy occurred only in the TAC group. This observation is supported by the study of Mueller [20], who showed a significantly higher incidence of NC in patients treated with TAC as compared with CS. However, both authors initially used the intravenous formulation of TAC, which is recognized as inducing more neurologic complications than TAC administered via the oral route. Freise [11] and Lewis [16] did not find higher rates of NC in patients treated with TAC as compared with CSA. These data are supported by the present study.

In conclusion, the present report emphasises the frequent development of NCs following liver transplant patients. A careful recognition, diagnosis of central nervous system lesions and prompt treatment is necessary.

Conflict of interest statement The authors have no financial or other potential conflicts of interest.

\section{References}

1. Adams DH, Ponsford S, Gunson B, Boon A, Honigsberger L, Williams A, Buckels J, Elias E, McMaster P (1987) Neurological complications following liver transplantation. Lancet 1:949-951
2. Adams RD, Victor M, Mancall EL (1959) Central pontine myelinolysis: a hitherto undescribed disease occurring in alcoholic and malnourished patients. AMA Arch Neurol Psychiatry 81:154-172

3. Boon AP, Carey MP, Adams DH, Buckels J, McMaster P (1991) Central pontine myelinolysis in liver transplantation. J Clin Pathol 44:909-914

4. Broelsch CE, Emond JC, Thistlethwaite JR, Whitington PF, Zucker AR, Baker AL, Aran PF, Rouch DA, Lichtor JL (1988) Liver transplantation, including the concept of reduced-size liver transplants in children. Ann Surg 208:410-420

5. Broelsch CE, Whitington PF, Emond JC, Heffron TG, Thistlethwaite JR, Stevens L, Piper J, Whitington SH, Lichtor JL (1991) Liver transplantation in children from living related donors. Surgical techniques and results. Ann Surg 214: 428-437; discussion 437-429

6. Bronster DJ, Emre S, Boccagni P, Sheiner PA, Schwartz ME, Miller CM (2000) Central nervous system complications in liver transplant recipients-incidence, timing, and long-term followup. Clin Transplant 14:1-7

7. Buckels JA (1995) Liver transplantation: current status, complications and prevention. J Antimicrob Chemother 36(suppl B):3949

8. de Brabander C, Cornelissen J, Smitt PA, Vecht CJ, van den Bent MJ (2000) Increased incidence of neurological complications in patients receiving an allogenic bone marrow transplantation from alternative donors. J Neurol Neurosurg Psychiatry 68:36-40

9. de Groen PC, Aksamit AJ, Rakela J, Forbes GS, Krom RA (1987) Central nervous system toxicity after liver transplantation. The role of cyclosporine and cholesterol. N Engl J Med 317:861-866

10. Ferreiro JA, Robert MA, Townsend J, Vinters HV (1992) Neuropathologic findings after liver transplantation. Acta Neuropathol 84:1-14

11. Freise CE, Rowley H, Lake J, Hebert M, Ascher NL, Roberts JP (1991) Similar clinical presentation of neurotoxicity following FK 506 and cyclosporine in a liver transplant recipient. Transplant Proc 23:3173-3174

12. Fruhauf NR, Koeppen Dagger S, Saner FH, Egelhof Dagger T, Stavrou G, Nadalin S, Broelsch CE (2003) Late onset of tacrolimus-related posterior leukoencephalopathy after living donor liver transplantation. Liver Transpl 9:983-985

13. Ghaus N, Bohlega S, Rezeig M (2001) Neurological complications in liver transplantation. J Neurol 248:1042-1048

14. Hinchey J, Chaves C, Appignani B, Breen J, Pao L, Wang A, Pessin MS, Lamy C, Mas JL, Caplan LR (1996) A reversible posterior leukoencephalopathy syndrome. N Engl J Med 334:494-500

15. Kim BS, Lee SG, Hwang S, Park KM, Kim KH, Ahn CS, Moon DB, Ha TY, Song GW, Kim DS, Moon KM, Jung DH (2007) Neurologic complications in adult living donor liver transplant recipients. Clin Transplant 21:544-547

16. Lewis MB, Howdle PD (2003) Neurologic complications of liver transplantation in adults. Neurology 61:1174-1178

17. Malago M, Testa G, Frilling A, Nadalin S, Valentin-Gamazo C, Paul A, Lang H, Treichel U, Cicinnati V, Gerken G, and Broelsch CE (2003) Right living donor liver transplantation: an option for adult patients: single institution experience with 74 patients. Ann Surg 238: 853-862; discussion 862-853

18. McDiarmid SV, Busuttil RW, Ascher NL, Burdick J, D'Alessandro AM, Esquivel C, Kalayoglu M, Klein AS, Marsh JW, Miller CM et al (1995) FK506 (tacrolimus) compared with cyclosporine for primary immunosuppression after pediatric liver transplantation. Results from the US Multicenter Trial. Transplantation 59:530-536

19. Moreno E, Gomez SR, Gonzalez I, Loinaz C, Garcia I, Perez A, Palomo C, Alvarado A, Maffettone V, Perez-Cerda F et al (1993) 
Neurologic complications in liver transplantation. Acta Neurol Scand 87:25-31

20. Mueller AR, Platz KP, Bechstein WO, Schattenfroh N, Stoltenburg-Didinger G, Blumhardt G, Christe W, Neuhaus P (1994) Neurotoxicity after orthotopic liver transplantation. A comparison between cyclosporine and FK506. Transplantation 58:155170

21. Pujol A, Graus F, Rimola A, Beltran J, Garcia-Valdecasas JC, Navasa M, Grande L, Galofre J, Visa J, Rodes J et al (1994) Predictive factors of in-hospital CNS complications following liver transplantation. Neurology 44:1226-1230

22. Saner F, Gu Y, Minouchehr S, Ilker K, Fruhauf NR, Paul A, Radtke A, Dammann M, Katsarava Z, Koeppen S, Malago M, Broelsch CE (2006) Neurological complications after cadaveric and living donor liver transplantation. J Neurol 253:612-617

23. Saner FH, Sotiropoulos GC, Radtke A, Fouzas I, Molmenti EP, Nadalin S, Paul A (2008) Intensive care unit management of liver transplant patients: a formidable challenge for the intensivist. Transplant Proc 40:3206-3208

24. Saner FH, Sotiropoulos GC, Gu Y, Paul A, Radtke A, Gensicke J, Kavuk I, Malago M, Broelsch CE (2007) Severe neurological events following liver transplantation. Arch Med Res 38:75-79

25. Saner FH, Koeppen S, Meyer M, Kohnle M, Herget-Rosenthal S, Sotiropoulos GC, Paul A, Radtke A, Malago M, Broelsch CE (2008) Treatment of central pontine myelinolysis with plasmapheresis and immunoglobulins in liver transplant patient. Transpl Int 21:390-391

26. Saner FH, Olde Damink SW, Pavlakovic G, van den Broek MA, Rath PM, Sotiropoulos GC, Radtke A, Canbay A, Paul A, Nadalin S, Malago M, Broelsch CE (2008) Pulmonary and blood stream infections in adult living donor and cadaveric liver transplant patients. Transplantation 85:1564-1568
27. Sila CA (1989) Spectrum of neurologic events following cardiac transplantation. Stroke 20:1586-1589

28. Starzl TE (2002) The saga of liver replacement, with particular reference to the reciprocal influence of liver and kidney transplantation (1955-1967). J Am Coll Surg 195:587-610

29. Starzl TE, Marchioro TL, Vonkaulla KN, Hermann G, Brittain RS, Waddell WR (1963) Homotransplantation of the liver in humans. Surg Gynecol Obstet 117:659-676

30. Starzl TE, Schneck SA, Mazzoni G, Aldrete JA, Porter KA, Schroter GP, Koep LJ, Putnam CW (1978) Acute neurological complications after liver transplantation with particular reference to intraoperative cerebral air embolus. Ann Surg 187:236-240

31. Stein DP, Lederman RJ, Vogt DP, Carey WD, Broughan TA (1992) Neurological complications following liver transplantation. Ann Neurol 31:644-649

32. Stracciari A, Guarino M (2001) Neuropsychiatric complications of liver transplantation. Metab Brain Dis 16:3-11

33. Valentin-Gamazo C, Malago M, Karliova M, Lutz JT, Frilling A, Nadalin S, Testa G, Ruehm SG, Erim Y, Paul A, Lang H, Gerken G, Broelsch CE (2004) Experience after the evaluation of 700 potential donors for living donor liver transplantation in a single center. Liver Transpl 10:1087-1096

34. Vogt DP, Lederman RJ, Carey WD, Broughan TA (1988) Neurologic complications of liver transplantation. Transplantation 45:1057-1061

35. Wijdicks EF, Plevak DJ, Wiesner RH, Steers JL (1996) Causes and outcome of seizures in liver transplant recipients. Neurology 47:1523-1525

36. Wright DG, Laureno R, Victor M (1979) Pontine and extrapontine myelinolysis. Brain 102:361-385 